\title{
Opportunities and challenges for the use of cleaner production to reduce water consumption in Brazilian sugar-energy plants
}

\author{
Manoel Gonçales Filho a, Thais Vieira Nunhes ${ }^{b}$, Luis César Ferreira Motta Barbosa ${ }^{\text {b }}$, \\ Fernando Celso de Campos ${ }^{a}$, Otávio José de Oliveira ${ }^{\text {b, * }}$ \\ a UNIMEP - Universidade Metodista de Piracicaba, Rod. Santa Bárbara/Iracemápolis, km 1 - Santa Bárbara dÓeste, Postal Code: 13.450-000, São Paulo, \\ Brazil \\ ${ }^{\mathrm{b}}$ UNESP - São Paulo State University, Guaratinguetá, Av. Ariberto Pereira da Cunha, 333 - Guaratinguetá, Postal Code: 12516-410, São Paulo, Brazil
}

\section{A R T I C L E I N F O}

\section{Article history:}

Available online 13 March 2018

\begin{abstract}
A B S T R A C T
Water is a finite and scarce resource that has gained importance in the global economic scenario. The sugar-energy plants use water intensively for the development of their activities, which demands that their top management incorporate actions to reduce or eliminate the use of this resource. In Brazil, the annual production of sugarcane is over 650 million tons/year and, on average, $1.18 \mathrm{~m}^{3}$ of water is consumed per ton of processed sugarcane. Given this, it is important to look for alternatives that allow the reduction of the volumes of water collection and use in Brazilian sugar-energy plants. The objective of this paper is to identify opportunities and challenges for using Cleaner Production (CP) to reduce water consumption in brazilian sugar-energy plants. To carry out this study, four case studies were conducted, whose data collection was based on semi-structured interviews with plant managers, document analysis and on-site visits. The case studies were analyzed individually, and then their cross-analysis were conducted in order to understand and present them in a transversal way to all the companies studied. Among the opportunities for improvement identified are the use of dry cleaning system for sugarcane cleaning, the classification and analysis of effluents, the analysis of the water consumption in the processes and the use of the system of concentration of vinasse. The main scientific contribution of this study is the systematization of CP interventions to reduce water consumption in sugar-energy plants, which expands the existing theory. The results of this work revealed that the opportunities and challenges presented may help companies to reduce considerably the volume of water used in their production systems, thus contributing to the preservation of the environment and the development of future generations.
\end{abstract}

() 2018 Elsevier Ltd. All rights reserved.

\section{Introduction}

Protecting the environment is an important factor to increase competitiveness and ensure business longevity (Zeviani et al., 2013). The impact of industrial activities on the environment has been inserted as an increasingly recurring element in corporate strategic planning, whether due to legal and social issues or due to opportunities for development of more productive process. Companies with successful environmental management programs have

\footnotetext{
* Corresponding author.

E-mail addresses: mlgoncales@unimep.br (M. Gonçales Filho), thais_nunhes@ hotmail.com (T.V. Nunhes), luiscesarfmb@gmail.com (L.C.F.M. Barbosa), fccampos@unimep.br (F.C. de Campos), otaviodeoliveira@uol.com.br (O.J. de Oliveira).
}

been achieving considerable improvements in their processes, in addition to keep a prominent position in the competitive market. Thus, the development of an efficient and effective environmental management program has been something commonly sought by organizations (Silva et al., 2017).

In this scenario, sugar-energy plants, which are usually known to cause significant impacts to the environment, seek new alternatives to mitigate these impacts, so that the development and management of their production processes can be conducted in a more sustainable way (Solomon, 2016; Kent and Scott, 2009). Sugar-energy plants, in general, are companies that produce sugar; hydrated ethanol and anhydrous fuel for vehicles; fertilizers from vinasse; alcoholic distillate; bio-based bulk materials (bio-plastic); energy from the bagasse of sugarcane, among other derivatives (Silalertruksa et al., 2017; Scheiterle et al., 2018). The sugarcane 
industry is considered one of the most attractive for investors among the agroindustries, mainly due to the potential of the plants in producing eletric power. Despite this, it is worth noting that the processing of sugarcane is characterized by the intensive use of water and the generation of potentially polluting waste (Birru et al., 2016).

The annual production of sugarcane in Brazil is over 650 million tons (crop 2013/2014), which makes it the largest producer of sugarcane worldwide (Silalertruksa et al., 2017). The volumes of water collection at the plants have decreased due to the environmental legislation and the implementation of an additional collection system for the use of water resources. However, it should be noted that, even so, the volumes of water abstraction that has been verified are large. Moving from a macro magnitude (Brazil) to a micro-magnitude (state of São Paulo, Brazil), it is worth noting that the sugar-energy plants in the State of São Paulo that are signatories of the Agro-environmental Protocol of the São Paulo sugar sector, which is based on voluntary accession of 176 sugar plants and 29 sugarcane suppliers, consumed on average, $1.18 \mathrm{~m}^{3}$ of water per tonne of sugarcane processed in the crop of 2013/2014 (Elia Neto et al., 2009).

Considering this scenario of great impact on the environment, it is important to highlight the importance of the sugar-energy plants using approaches that facilitate the inclusion of environmental practices in their processes. One of these approaches is the Cleaner Production (CP), which can be an environmental program that involves interventions of three levels: (1) changes in products and processes; 2) internal recycling of waste; and 3) external recycling of waste (Medeiros et al., 2007).

$\mathrm{CP}$ has a challenging task facing industrial companies around the world, impacting not only on the management operations but also on the strategic planning (Zhou et al., 2012). In this sense, the management of sugar-energy plants, through the fundamentals of Cleaner Production, can be used to replace traditional procedures and equipment to other more eco-efficient ones that can reduce or eliminate water use and minimize the generation of effluents and waste, thus making the process more sustainable.

The relevance of the present work is highlighted by considering the importance of the water use situation in the production process of sugar-energy plants. Given this, the objective of this study is to identify opportunities and challenges for using Cleaner Production in Brazilian sugar-energy plants, in order to reduce, at the lowest possible levels, the volumes of water used in companies of this segment. Throughout this article will be presented and compared, from a theoretical and empirical point of view, the use and reuse of water practices in the production process of Brazilian sugar and ethanol plants, in order to identify opportunities and challenges of using Cleaner Production in companies of this segment.

The next section presents a synthesis of the theoretical framework that provided basis for the development of this work. The topics approached in the theoretical framework were Cleaner Production and general characteristics of Brazilian sugar-energy plants. Subsequently, the research method is presented, the multiple case studies are exposed and analyzed comparatively. Soon after, the results are discussed in light of the Cleaner Production theory and intervention proposals are presented. Finally, the conclusions generated from the analysis are presented.

\section{Synthesis of the theoretical framework}

This section presents a synthesis of the theoretical framework on Cleaner Production (CP) and on the general characteristics of Brazilian sugar-energy plants.

\subsection{Cleaner Production}

Cleaner Production (CP) is the harmonious design of products and production processes with the natural ecological cycles, using the available resources efficiently and searching for the use of harmless substances in the production processes (Zeng et al., 2010). The practice of CP can bring several benefits to organizations, such as reduced waste in processes, lower operating costs, improvements in the economic performance of production, quality, and customer service, improved image towards clients and society, increased competitiveness, etc. (Shi et al., 2008; Silva et al., 2013). However, many organizations find it difficult to implement actions based on this methodology due to limitations of conceptual, technical, political, hierarchical, economic and financial nature (Santos et al., 2015; Silva et al., 2017).

$\mathrm{CP}$ goes beyond the search for reducing of the adverse effects of the companies on the human beings and environment, also seeking to raise the efficiency of the production and the levels of sustainability (Laforest et al., 2012; Van Hoof and Lyon, 2013). CP focuses on the elimination and minimization of waste and emissions generated in its sources, rather than attempting to act at the end of the process ("end of pipe"). CP has emphasis on the environmental issue in all phases of the design and manufacturing processes, that is, from the raw material, manufacture, production and disposal of effluents and waste (Silva et al., 2013).

According to Getzner (2002), CP comprises a detailed diagnosis of the activities of the productive system in order to analyze the impacts, causes, and effects of the actions and, if possible, the proposition of alternatives solutions that are more sustainable than those already used in terms of technological changes and to the forms of management.

Some important actions for the application of $\mathrm{CP}$ are: i) to continually apply the integrated environmental strategy for products and processes aimed at reducing risks to humans and the environment; ii) using techniques to reduce the use of raw materials and energy and reduce the toxicity of emissions and waste; iii) developing strategies that focus on reducing environmental impacts throughout the product life cycle; and iv) seek continuous improvement through the application of periodic evaluations to the $\mathrm{CP}$ program and training to raise awareness of the whole workforce (Bueno and Salvador, 2012).

From a practical point of view, CP involves activities such as monitoring air quality, controlling water pollution, saving energy and minimizing the generation of waste and effluents. Some examples of wastes that can be found in the industry and that must be managed are wastewater from the production process, effluents from the raw material cleaning, lubricating oil from equipments, fusel oil, grease, vinasse, among others the oily wastes, solvents, effluents originated from the productive processes, among others (Molinaria et al., 2013).

The use of a CP program can generate benefits to industrial companies, such as: lower operating costs, significant reduction in energy consumption and waste generation, reduction of emissions that cause environmental pollution, improvements in the economic performance of production, quality, and customer service. Regarding the challenges of implementing $\mathrm{CP}$, it is worth mentioning political and market difficulties, financial and economic, technical and informational and managerial and organizational difficulties (Werner et al., 2009; Silva et al., 2013).

According to Liu (2014), the use of old and inefficient technologies, the lack of information on new green technologies and insufficient production infrastructure are examples of problems that may hinder the implementation of CP. For an effective implementation of $\mathrm{CP}$ we must guarantee some essential aspects, namely: i) safe manufacturing systems and production processes; 


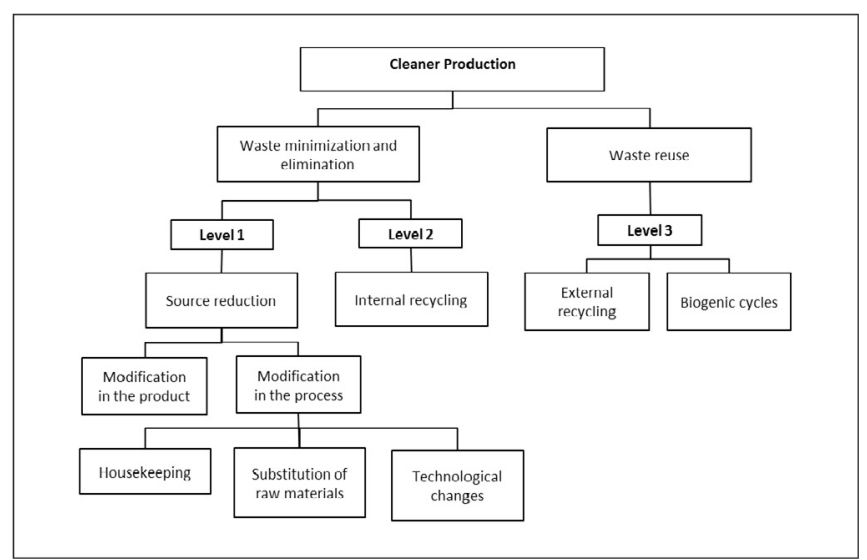

Fig. 1. Cleaner Production intervention levels. Source: Based on Medeiros et al. (2007).

ii) non-toxic, recyclable and reusable clean products; iii) closed loop systems, reusing materials and recycling, in order to keep a more sustainable process (Hoof and Thiell, 2015).

$\mathrm{CP}$ involves the implementation of actions that can be classified into three levels, as indicated in Fig. 1.

Level 1 actions are related to changes in products and processes that seek to reduce or eliminate waste generation through, for example, improvements in the production process, substitution of products and raw materials for other less polluting substances, and technological changes. At the level 2, the actions of internal recycling stand out, that is, the organization reintegrates its waste into the production process as a raw material of equal, different or superior to the original use. On the other hand, the actions classified as level 3 are those that involve the reuse of waste through external recycling to the company (Medeiros et al., 2007).

\subsection{General characteristics of Brazilian sugar-energy plants}

Brazil, which produces ethanol from sugarcane, is the world's second largest producer of ethanol behind only the United States, which produces it from corn, at a cost that is three times higher than the sugarcane by-product (Rodrigues, 2011). Up to 2015 there were 342 active plants installed in the Brazilian territory and another 46 inactive. Among them, the largest plants processed, on average, 7,690,200 tons of sugarcane per crop (2013-2014) (Novacana, 2015). In this sense, it should be noted that large volumes of sugarcane production are of vital importance for maintaining and increasing the profitability of the sugar-energy sector.

In sugar plants, sugar cane can have two destinations: sugar or ethanol production. Both products have the same initial stages of production, which are: (i) reception and cleaning of the sugarcane; (ii) extraction of the broth (by means of milling or diffusion); (iii) treatment/evaporation and purification of the broth: sieving and clarification.

For sugar production, the following steps are: (iv) turbinating and cooking; (vi) sugar crystallization; (vii) filtration, cooling and drying for separation between crystals and cooked mass (demerara and white sugar).

For production of ethanol the following steps are: (iv) fermentation of the broth; (v) distillation of wine; (vi) dehydration: anhydrous or hydrated alcohol (Rodrigues et al., 2014). As the companies studied are ethanol producers, this will be the main focus of this work.

The production process of the sugar-energy plant begins with the reception of sugarcane, which is cleaned with water or dry; followed by milling, juice treatment, cooking and centrifugation, fermentation, distillery, dehydration. The process of cleaning with water generates the sugarcane cleaning effluent, whose composition consists of water, soil and straw (Rodrigues et al., 2014). The full description of the production stages of the sugar-energy plants and its residues and effluents will be presented later, in Fig. 3 of section 4 - case studies.

A study conducted by Omena et al. (2004) pointed out that Brazilian sugar-energy plants mix, on average, $50 \%$ of good quality water with $50 \%$ of low quality water (which is returned from the decanter) for cleaning sugarcane. Moreover, the addition of milk of lime was verified to correct the water $\mathrm{pH}$. These measures are needed because the water that returns from the decanter contains solids and sugars that favor fermentation and decrease its $\mathrm{pH}$.

Sugarcane ethanol is one of the main renewable fuels for transportation, since it is clean, affordable and has low carbon biofuel (Figueiredo, 2017). However, to analyze how clean the product itself is, one must look at the way in which it is produced and the impacts of that production on the environment (Silalertruksa et al., 2017).

In this sense, Stupiello (2014) reports that environmental measures, especially related to the consumption of water and sugar losses in the cleaning of sugar cane, obliged the Brazilian plants to stop washing the sugar cane to use a dry cleaning system. As a result, several dry cleaning projects were installed at the sugarcane receptions of many plants. Despite this, it should be noted that there are still many opportunities that can be taken advantage of by

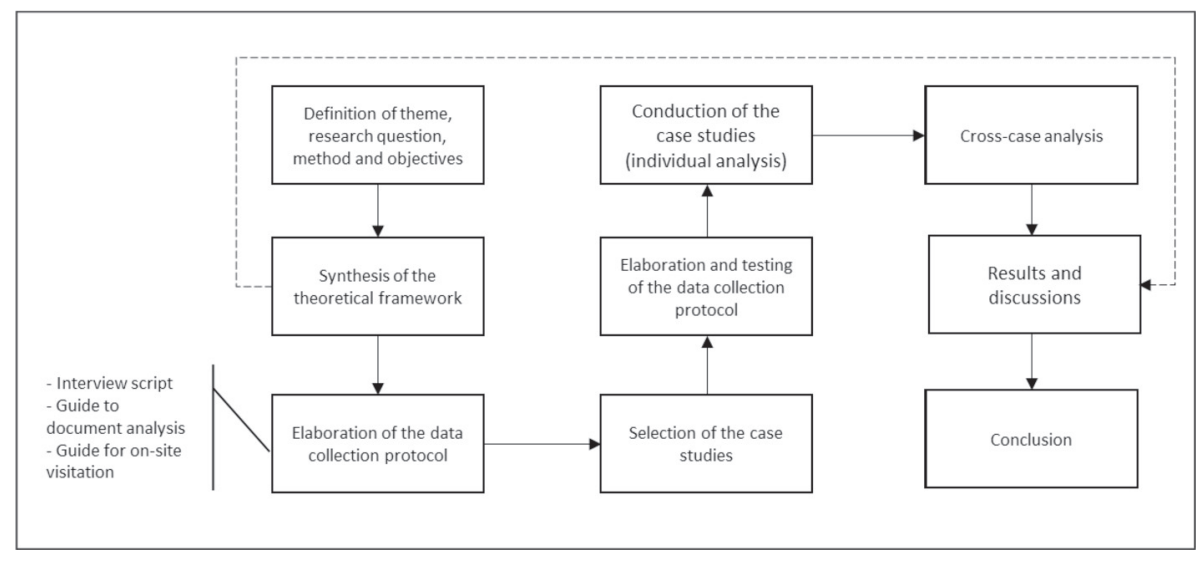

Fig. 2. Methodological flow. 


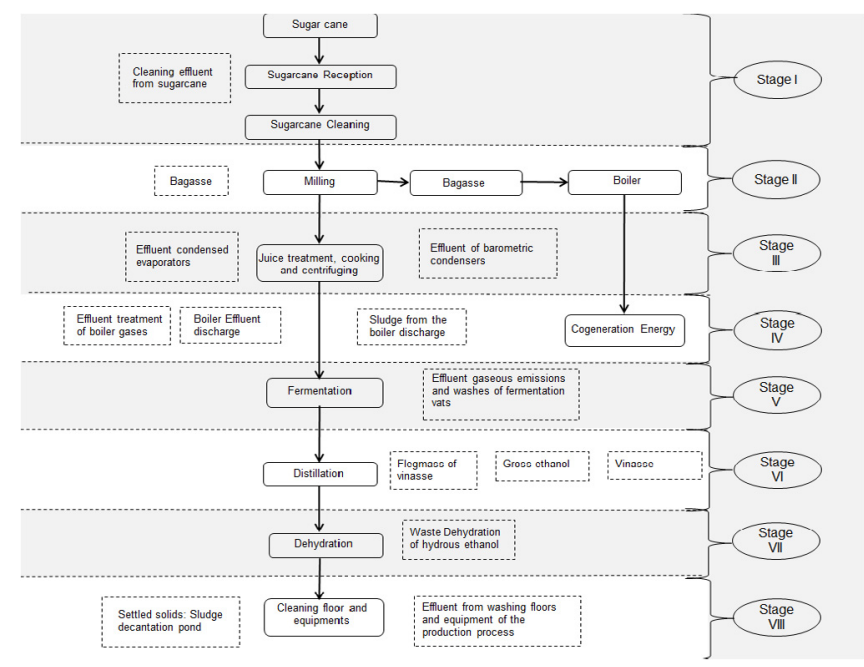

Fig. 3. - Production stages of the sugar-energy plants and its waste and effluents.

the plants to eliminate waste and reduce waste deposited in the environment.

Some environmental impacts of final products of sugarcane are climate change, terrestrialacidification, human toxicity, particulate matter formation, terrestrial ecotoxicity, freshwater ecotoxicity, fossil depletion, etc. These impacts can result from cane trash burning before harvesting, open lagoon systems for wastewater treatment, use of chemical fertilizers, among others (Silalertruksa et al., 2017).

Therefore, this work will present some of these opportunities and also the challenges faced by Brazilian sugar-energy plants to use the $\mathrm{CP}$.

\section{Research method}

This research is qualitative, developed based on the multiple case studies method. Qualitative research focuses on the meanings and interpretation of phenomena in the particular context in which they occur (Jupp, 2006). Therefore, the multiple cases studies method was adopted in order to conduct a study of a phenomena in different realities, in this case, 4 (four) organizational realities. Case studies are an appropriate approach to answering in a deep and detailed way questions such as "how" and "why", making it possible to identify good practices, opportunities for using $\mathrm{CP}$, among other information used in this study (Yin, 2014).

Moreover, it should be noted that taking into account the limitation of sector and region applied to this study, we had few companies available to participate in it, which therefore also corroborates the choice of the case studies method to accomplish the work.

The case studies of this work were planned taking into account the project tests to carry out case studies proposed by Yin (2014), with the objective of guaranteeing the reliability of the results. The results of the test of the case studies project are presented in Table 1.

Table 1 shows that the tactics recommended by Yin (2014) for the conduction of case studies were considered in this work in order to ensure the quality of the case studies regarding the validity of the construct, external validity and reliability. It should be noted that the internal validity of the case studies was not assessed, because it is not applicable to descriptive or exploratory studies, which are not concerned with making causal propositions (Yin, 2014).

The methodological flow according to which the research was developed is composed of nine main steps, as shown in Fig. 2. In the first step, the key elements of the research were defined, such as theme, research question, objective and research method. After that, the theoretical framework and the data collection protocol was elaborated. Then, the cases were selected, delimiting the study to the plants presented at the state of São Paulo, Brazil.

The protocol contained elements related to the three sources of evidence used in the data collection: semi-structured interview, document analysis and on-site visit. According to Sampieri et al. (2006), it is important for researchers to have, from multiple sources of evidence and distinct situations, a reasonable set of data so as to ensure the reliability and validity of the study and its findings. In order to select the plants to be surveyed, the following criteria were considered: the sugar-energy plants should be Brazilian and have, at least, a rationalization project of water use. During the on-site visits, all stages of the production process were analyzed and the production manager and the process manager of the plant of each of the companies surveyed were interviewed, using the interview script available in Appendix A. The characteristics of the companies studied are shown in Table 2.

As can be seen in Table 2, the plants A, B, C, and D have approximately 600, 500, 1850 and 530 employees. All plants are

Table 1

Test of the case studies project.

\begin{tabular}{|c|c|c|}
\hline $\begin{array}{l}\text { Case study } \\
\text { project test }\end{array}$ & Forms of evaluation of the case studies' projects & Results of evaluation of the case studies of this study \\
\hline \multirow[t]{3}{*}{$\begin{array}{l}\text { 1) Validity of } \\
\text { the construct }\end{array}$} & 1.1) Using multiple fonts of evidence & $\begin{array}{l}\text { Three instruments were used as sources of simultaneous evidence for } \\
\text { data collection: document analysis, on-site visits and interviews. }\end{array}$ \\
\hline & 1.2) Establishing synergy between evidences & $\begin{array}{l}\text { The synergy between evidences was contemplated through explicit } \\
\text { links between the questions asked, the data collected and the } \\
\text { conclusions reached. }\end{array}$ \\
\hline & 1.3) Reviewing the draft report of the case studies by key informants & $\begin{array}{l}\checkmark \text { The drafts of the case study reports were reviewed by the informants } \\
\text { - that is, those people who were objects of the study. }\end{array}$ \\
\hline $\begin{array}{l}\text { 2) Internal } \\
\text { validity }\end{array}$ & $\begin{array}{l}\text { 2.1) To carry out an assessment of the appropriateness to the standard } \\
\text { 2.2) To carry out a construction of the explanation } \\
\text { 2.3) Analyzing the time series }\end{array}$ & $\begin{array}{l}\text { It is not applicable to descriptive or exploratory studies, which are not } \\
\text { concerned with making causal propositions. }\end{array}$ \\
\hline $\begin{array}{l}\text { 3) External } \\
\text { validity }\end{array}$ & 3.1) Using replication logic in multiple case studies & $\checkmark$ Multiple case studies were conducted. \\
\hline 4) Reliability & $\begin{array}{l}\text { 4.1) Using case study protocol } \\
\text { 4.2) To develop database for the case study }\end{array}$ & $\begin{array}{l}\checkmark \text { The case study protocol was elaborated. } \\
\checkmark \text { A formal database containing information independent of any } \\
\text { opinion made by the original investigator was created so that other } \\
\text { researchers can review the evidences. }\end{array}$ \\
\hline
\end{tabular}


Table 2

Main characteristics of the companies studied.

\begin{tabular}{|c|c|c|c|c|}
\hline Company & Number of employees & $\begin{array}{l}\text { Sugarcane Processing } \\
\text { Capacity (Ton/month) }\end{array}$ & $\begin{array}{l}\text { Signatory of the Agro- } \\
\text { environmental Protocol? (Yes/No) }\end{array}$ & $\begin{array}{l}\text { Is it use projects of water } \\
\text { rationalization? (Yes/No) }\end{array}$ \\
\hline A & 600 & 240.000 & Yes & Yes \\
\hline B & 500 & 210.000 & No & Yes \\
\hline C & 1850 & 720.000 & Yes & Yes \\
\hline $\mathrm{D}$ & 530 & 210.000 & Yes & Yes \\
\hline
\end{tabular}

signatories to the environmental protocol, with the exception of plant B. All the plants surveyed have rationalization projects for water use.

Further information about the four participating plants will be detailed throughout section 4 , case studies. To obtain a better knowledge about the technological options in use on sugarcane plants for minimizing water use, two senior researchers from EMBRAPA (Brazilian Agricultural Research Company) were also interviewed. EMBRAPA is a public research institution linked to the Ministry of Agriculture, Livestock and Supply of Brazil that is a reference in technological innovation and sustainability (EMBRAPA, 2017).

In the technical visits to the plants, there was access to their management documentation, which facilitated the understanding of operational and management aspects of the process as a whole, from reception until dispatch area. Thus, the case studies were analyzed individually, and then their cross-analysis were conducted in order to understand and present them in a transversal way to all the companies studied, as indicated by Martins (2010). The case studies reports were reviewed by the production managers of the plants surveyed to ensure the reliability and validity of the analyzes. Section 4 presents the results and analysis of the case studies. Finally, section 5 presents the opportunities and challenges for $\mathrm{CP}$ use in sugar-energy plants, based on the results of the case studies, the CP theory and the experience of the authors of this article. This section is followed by the conclusions of the study.

\section{Presentation and analysis of the case studies}

In this section the characterization of the productive process of the companies studied is presented, highlighting considerations on the destination of waste and effluents, quantity of water consumed and its costs, etc. The production process of the companies studied can be divided into eight main steps, as shown in Fig. 3. In this Figure, the residues and effluents are presented with dashed line to illustrate in which stage of the productive process they are generated.

In the first stage, the reception and cleaning of the sugar cane is done and effluents resulting from this cleaning are generated. In stage 2 , the sugarcane is ground and as by-product of this process is generated the bagasse, which is sent to the boiler. In stage 3 , the sugarcane juice is treated, cooked and centrifugated. This stage generates the condensed effluent from the evaporators and the barometric condensers.

In stage 4, the process of energy cogeneration is carried out and the effluents related to this stage are the effluent from the treatment of the boiler gases and the discharge effluent from the boiler. In stage 5 , the fermentation takes place, which generates the effluent from the gas emissions and from the washes of the fermentation vats. In stage 6 the distillation is done, which generates residues from the rectified solution of phlegma, ethanol and vinasse. Finally, in stage 7 the ethanol is dehydrated, which generates residues resulting from this process, and in stage 8 it is carried out the washing of the floors and equipment, which also generates effluents resulting from washing.

In Brazil there is a maximum value for river water collection, and for this purpose, it is necessary to obtain the release of the water collection concession term by the National Water Agency (ANA) and/or the Department of Water and Electrical Energy (DAEE). These bodies require the mandatory implementation and maintenance of a hydrometer for continuous control of the flow captured by the granted. Thus, in case the limit of water collection permitted is exceeded, the grantor is subject to inspection, and can be penalized with fines if the surpluses are effectively verified.

Out of a total of 22 types of effluents and residues generally found in a sugar-energy plant (reviewed in the literature), 13 were verified in the companies studied. These 13 effluents are generated by the sugar-cane processing and have water in its final composition. They are effluents and residues from the cleaning of the reception of sugarcane, effluent from the treatment of the combustion gases of the boiler, effluent from the discharge of boilers, sludge, condensed effluent from evaporators, effluent from barometric condensers, rectified solution of phlegma, ethanol, vinasse, residues from dehydration of ethanol, effluent from cleaning floors, equipment, vats, and decanted solids.

The daily volumes of sugarcane for grinding every $24 \mathrm{~h}$, in tons, is 8000 in the plant A, 7000 in the plants B and D, and 24,000 in the plant $C$. Regarding the cleaning of sugarcane before starting the process, it was observed that only the plant B does not clean the sugarcane before starting the grinding, i.e., the raw material enters in the productive process with various impurities, such as straw, stone, soil, etc. In this case, the managers recognize the large amount of impurities entering the process.

According to Payne (1990), the process of cleaning sugar cane before the production process is necessary in order to eliminate unwanted mineral and vegetable materials, which may impact the productivity of the equipment. The natural microbial load on the sugar cane surface can also be harmful, and the lack of performing this cleaning can lead to the presence of microorganisms in the process that would reduce the efficiency of the fermentation step (Elia Neto et al., 2009).

It was also identified that the use of water at the reception of sugar cane occurs at plants $A$ and $D$, while plant $D$ has the two types of cleaning: with water and dry. Plant $C$ does not use water for cleaning sugar cane, that is, it only performs dry cleaning; while plant B does not carry out any type of cleaning. Both plants A and D, which use water at the reception of sugarcane, recognize the importance of this resource and treat the waste water before returning it to the environment.

There is a direct relation of this water use according to the type of sugarcane that is arriving, that is, all the plants have the options of receiving the whole and/or chopped sugarcane. The whole sugar cane is obtained by manual harvesting on uneven terrain, and the chopped sugar cane is obtained by means of mechanized harvest in flat terrain. The use of mechanized harvesting has increased over the years in all sugar cane plants, mainly for reasons of Brazilian legislation.

Another aspect verified concerns the possibility of separation of 
the sugarcane straw at the reception and its transport to the boiler. In plants $C$ and $D$ the straw is separated from the sugar cane and is used for energy purposes. It should be noted that the use of straw in this case does not interfere in the cycles of nature, because at the time of harvest, the mechanized equipment leaves enough amount of straw on the ground, which is used as fertilizer by increasing $\mathrm{P}, \mathrm{K}$, $\mathrm{Ca}, \mathrm{Mg}$ and others nutrients in the soil (Silalertruksa et al., 2017). Plants $\mathrm{A}$ and $\mathrm{B}$, however, do not separate the straw at the reception.

Regarding the destination of the water used by the plants after the cleaning of the sugarcane, the plants A and D destine this waste water for the decantation lake. In this way, once decanted, the water returns to cleaning the sugarcane at the reception of the process. Plant A reuses water in the cleaning of sugarcane more than five times; the plant $\mathrm{D}$, at most, two; and plant $\mathrm{C}$ do not control the number of times it reuses water.

Plant D performs the water pumping for the cleaning of the sugarcane from a closed circuit of the sugar cane washing water, from the barometric columns of the distillery condensers and from the cooling of the vats and most. This means for the plant D an additional equipment in use (pump), more electricity consumption, more maintenance, more hours and resources for controls, among others.

The waste and effluent, such as bagasse can be intended for use in the generation of energy and as an alternative raw material for wood pulp in the paper industry (Kheerthipala, 2016; Solomon, 2016). In general, the residues have compositions that make it impossible dispose it in the environment, thus requiring treatments to enable its reuse or disposal without causing environmental damages.

The cleaning effluent at the reception of sugarcane has in its composition water, soil, straw and high biochemical oxygen demand, what make it improper for being released into bodies of water. Therefore, Plants A and D have destined the cleaning effluent to fertigation (irrigation of sugar cane) by vertical and horizontal integration and recirculation. The vertical fertigation is the cultivation by the plant itself on its properties and/or on leased land. The horizontal fertigation is the outsourced cultivation, and the recirculation is the reuse in the production process.

The effluent from the treatment of the combustion gases of the boiler is the result of the cogeneration of energy. After its treatment in a sedimentation tank, one of the destinations for this effluent is the recirculation in the stage of cleaning the sugar cane, what is done by plants A and D. Plants B and C, at the end of the harvest, use the effluent in the tillage (vertical and horizontal integration) from its incorporation to the vinasse. From the environmental point of view, the use of this effluent in a closed circuit is more adequate, since this attitude reduces the need of water collection at the sources. However, its use in the tillage is also environmentally appropriate.

Regarding the discharge effluent from the boilers, it is also residue from the cogeneration stage. All the companies studied use this residue in the tillage (vertical and horizontal integration) by incorporating it to vinasse. As it is an effluent with low biochemical oxygen demand, this practice is considered adequate from the environmental point of view.

Sludge is a residue from the discharge of the boilers and it is also a residue of cogeneration. Its main destination is the application in the field and landfill areas. All the research plants incorporate this material to the filter cake and use the product for application in the tillage (vertical and horizontal integration), which constitutes an environmentally adequate attitude due to the low biochemical oxygen demand of the product.

The condensed effluent from the evaporators can be reused, depending on the level of contamination, in low pressure boilers and in the industrial process, or for cleaning floors and equipment.
Because it is a hot effluent, plants A and B use it in the boilers. Plants $\mathrm{C}$ and $\mathrm{D}$ incorporate it to the vinasse to be used in the tillage.

The effluent from barometric condensers is generated in the stages of concentration of the broth and baking of the mass. There are two common destinations to this effluent: recirculation to the process after treatment (cooling) or discharge in bodies of water, respecting the applicable quality standards of the receiving body. Plant A uses this effluent in the ethanol distillation process and plants B, C and D use it in the tillage.

The rectified solution of phlegma is a water with traces of fusel oil, which is added to the vinasse or wastewater, used for the cleaning of fermentation vats and heat exchangers, or marketed (the oil) after its decantation. The plants A, C and D reuse it in the process and/or commercialize the oil after decantation, which is an environmentally adequate and preferable option, since it reduces the need to collect water. Plant B, in turn, aggregates this residue to the vinasse and applies it directly to the tillage (vertical and horizontal integration).

The ethanol returns to the vast (productive process) and is aggregated to the bagasse, in order to increase its calorific value. Plants $A$ and $D$ have reincorporated it into the ethanol production process, while plants $B$ and $C$ market it.

Vinasse is a pasty and smelly residue that remains after the fractional distillation of the fermented sugar cane juice. For each liter of alcohol produced, in average, $12 \mathrm{~L}$ of vinasse is left as residue. The four companies studied use vinasse in fertigation, which is better when compared to the old practice of discharging in rivers and springs, when the environment was harmed by its chemical composition.

The waste from the dehydration of ethanol is dumped in landfills in all the companies studied. Regarding the effluent from the cleaning of floors and equipment, it should be noted that all the companies studied incorporate this effluent into the vinasse, with consequent application in the tillage. This destination is considered environmentally adequate as long as the separation of the oil is properly carried out.

The cleaning effluent of the vats is a residue generated throughout the productive process. It has a polluting effect similar to vinasse, although more diluted. In this way, its destination is usually the same destination given to vinasse, that is, fertigation. All the companies studied incorporate this effluent to the vinasse and destine it to the fertirrigation (vertical and horizontal integration), which is environmentally adequate.

The decanted solids are residues generated during the production process which, when without oil residues, follow to the disposal in the tillage. If oil residues are detected, the decanted solids are destined to the recycling companies. All the companies studied destine this effluent to the tillage (vertical and horizontal integration), which is considered an environmentally adequate destination. Table 3 shows a summary of the waste and effluent destination in the four companies studied.

Some initiatives to improve the eco-efficiency of the production processes through the rationalization of water use have already been used by the companies studied. In this sense, plants $C$ and $D$ have invested in the installation of cooling towers and in the reuse of water in some operations of the plant, leading to average savings of $5 \%$ less water used in the total water balance of the plants.

In addition, plants $A, C$ and $D$ have carried out the installation of the deaerator, which is useful to remove gases such as carbon dioxide and oxygen present in the water, so that there is no corrosion of the wall of the boiler piping. It is an important attitude because the solids from the bagasse, such as sand, are abrasive and, thus can damage and perforate the boiler piping. In this way, the deaerator can increase the life of the boiler and, consequently, its energy efficiency. Plant $C$ replaced the heat exchangers to plates by chillers of 
Table 3

Waste and effluent destination.

\begin{tabular}{|c|c|c|c|c|}
\hline \multirow[t]{2}{*}{ Waste and effluents } & \multicolumn{4}{|l|}{ Disposal of waste and effluents } \\
\hline & A & $\mathrm{B}$ & $\mathrm{C}$ & $\mathrm{D}$ \\
\hline Cleaning effluent from sugarcane & Production process and tillage & - & - & Production process and tillage \\
\hline Effluent from treatment of flue gases & Cleaning of sugarcane & Vinasse and tillage & Vinasse and tillage & Cleaning of sugarcane \\
\hline Discharge effluent from boilers & Vinasse and tillage & Vinasse and tillage & Vinasse and tillage & Vinasse and tillage \\
\hline Sludge & Pie and tillage & Pie and tillage & Pie and tillage & Pie and tillage \\
\hline Condensed effluent from evaporators & Boilers & Boilers & Vinasse and tillage & Vinasse and tillage \\
\hline Effluent of barometric condensers & Distillation of ethanol & Tillage & Tillage & Tillage \\
\hline Rectified solution of phlegma & Production process/markets & Vinasse and tillage & Production process/markets & Production process/markets \\
\hline Crude ethanol & Ethanol production & Markets & Markets & Ethanol production \\
\hline Vinasse & Tillage & Tillage & Tillage & Tillage \\
\hline Residues from dehydration of ethanol & Landfills & Landfills & Landfills & Landfills \\
\hline Effluent from washing floors and equipment & Vinasse and tillage & Vinasse and tillage & Vinasse and tillage & Vinasse and tillage \\
\hline Effluent from washing vats & Vinasse and tillage & Vinasse and tillage & Vinasse and tillage & Vinasse and tillage \\
\hline Solid decanted & Tillage & Tillage & tillage & tillage \\
\hline
\end{tabular}

reduction of temperature in the fermentation of the must. With the heat exchangers the consumption of water is about $3-4 \%$ of the total water balance, and with the implementation of the chillers this consumption is rationalized to $2-2.5 \%$.

Plants A and D reuse water from the effluent of treatment of flue gas in the cleaning of sugarcane. In order to do so, these plants (A and $\mathrm{D}$ ) have adopted systems with closed circuits for water reuse, which enabled them to minimize the consumption of this resource. The plants $C$ and $D$ have also replaced the traditional cleaning with water by the dry-cleaning system, which enabled them to achieve considerable savings in terms of water use in the processes and costs related to its abstraction and management.

Considering a harvest of 245 days with 24 working hours, it is possible to estimate the total consumption of water per harvest (in liters) used in the production process. Table 4 shows the consumption and abstraction of water per plant.

In general terms, it was observed that small plants (B and D) consume and capture, on average, 3 billion liters of water from rivers during a harvest, while medium and large plants (A and $C$ ) consume and collect, on average, over the same period 4 billion liters of water. Table 5 presents the costs of water collection and consumption per harvest in the companies studied.

It can be seen in Table 5 that the plants A and B capture and consume even more water than the others companies studied, since they use 1-2 cubic meters of water per ton of processed sugar cane and have in average, per harvest, the cost of US\$ $35.272,18$. It should be noticed that both plants produce an average of 7500 tons of sugarcane a day with 24 working hours, possibly because they have not yet been able to adopt some measures to rationalize their water consumption.

On the other hand, plants $C$ and $D$ have their water use reduced by up to 1 cubic meter per ton of processed sugarcane. These plants have dry cleaning, cooling tower, reuse of water contained in the effluent, closed systems for water use and reuse, chillers replacing

Table 4

Consumption and total abstraction of water per harvest.

\begin{tabular}{lll}
\hline Plant & $\begin{array}{l}\text { Daily volume of } \\
\text { processed sugarcane }\end{array}$ & $\begin{array}{l}\text { Total volume (in liters) of water } \\
\text { used in the production process }\end{array}$ \\
\hline A & 8.000 & 3.920 .000 .000 \\
B & 7.000 & 3.430 .000 .000 \\
C & 24.000 & 4.116 .000 .000 \\
D & 7.000 & 1.715 .000 .000 \\
\hline Total & 46.000 & 13.181 .000 .000 \\
\hline
\end{tabular}

heat exchangers (the latter only in the plant $\mathrm{C}$ ). Plant $\mathrm{C}$ consumes a volume below $0.7 \mathrm{~m}^{3}$ per ton of processed sugar cane, which means that, consequently, its cost of water consumption and abstraction is proportionally lower than in the other plants (on average US\$ $39.506,85$ processing 15,500 tons of sugarcane for $24 \mathrm{~h}$ per day). This means that, on average, plant $C$ produces twice the plants $A$ and $\mathrm{B}$ have produced and at a lower cost.

\section{Identification of opportunities and challenges for using Cleaner Production in Sugar-Energy Plants}

In this section the results of the case studies are discussed and used to identify opportunities and challenges for achieving improvements in sugar-energy plants in light of the CP theory. The improvement opportunities and challenges presented below were proposed based on the theoretical framework of this work, and on the discussion of the results of the case studies.

\subsection{Using the dry-cleaning system}

The reception of the sugar cane can be done on inclined table or on the conventional table, where the cane is washed to remove the impurities. In this stage, there is an opportunity to reduce water consumption by using the dry-cleaning system instead of the traditional cleaning system.

Based on the results of this research, it was noted that there are environmental and economic advantages for the use of drycleaning in sugar-energy plants, which include the elimination of water consumption in the cleaning of sugarcane and, consequently, elimination of the effluent of this stage; reduction of costs with water, lime and labor to manage the effluent disposal; no loss of sugar content, etc.

However, it should be noted that the investment in dry cleaning equipment is high. Nevertheless, investments in CP actions can result in greater economic and competitive value to companies, which in turn can raise the level of production through the use of less inputs and the reduction of waste generation (Zeng et al., 2010).

\subsection{Carry out the classification and analysis of the effluents}

The plants must comply with environmental standards established by law, giving due attention to the proper disposal of their effluents and waste (Klemes et al., 2012). For this, an analysis of the effluents can be done by means of its classification according to the three levels of intervention of the $\mathrm{CP}$, presented in the theoretical reference of this study (Medeiros et al., 2007). An example of 
Table 5

- Costs of water consumption per harvest in the companies studied.

\begin{tabular}{llll}
\hline Plant & $\begin{array}{l}\text { Cost of water } \\
\text { consumption (US\$) }\end{array}$ & $\begin{array}{l}\text { Cost of water } \\
\text { extraction (US\$) }\end{array}$ & Total (US\$) \\
\hline A & $12.539,19$ & $25.077,17$ & $37.616,36$ \\
B & $10.973,54$ & $21.954,46$ & $32.928,00$ \\
C & $13.166,14$ & $26.340,71$ & $39.506,85$ \\
D & $5.487,82$ & $10.014,88$ & $15.502,70$ \\
Total & $42.166,69$ & $83.387,22$ & $125.553,91$ \\
\hline
\end{tabular}

Table 6

Example of classification of waste and effluents.

\begin{tabular}{llcl}
\hline Waste and effluents & \multicolumn{2}{l}{ Levels of CP for waste and effluents } \\
\cline { 2 - 4 } & 1 & 2 & 3 \\
\hline Efluent A & $\mathrm{x}$ & $\mathrm{x}$ & \\
$\begin{array}{l}\text { Efluent B } \\
\text { Waste A }\end{array}$ & $\mathrm{x}$ & & $\mathrm{x}$ \\
Waste B & & & \\
\hline
\end{tabular}

classification of waste and effluents according to the $\mathrm{CP}$ intervention levels is presented in Table 6 .

The classification of waste and effluents presented in Table 6 can be conducted by classifying its destination according to the $\mathrm{CP}$ levels. Therefore, the waste or effluent is classified at the level 1 when it is treated through technological changes that imply in modifications in the product or process, level 2 when it is sent for internal recycling, and level 3 when it is sent for external recycling. Effluents A, B, C and so on presented in Table 6 can be any type of effluent generated in the company, which should classify them according to the above-mentioned recommendations.
Table 7 presents some possibilities of interventions for the disposal of waste and effluents by sugar-energy plants and its classification according to the $\mathrm{CP}$ intervention levels.

Table 7 presents some options for interventions to eliminate waste and effluents, however, it is possible that other possibilities may be adopted, depending on the reality of the companies.

\subsection{Using the vinasse concentration system}

Stone (2010) emphasized that the actions of CP involve the standardization of processes, investments in training and control, improvements in the use of machinery and equipment, use of less toxic materials, use of mechanical rather than chemical or physical processes, and reuse of materials, structures and energy whenever possible.

In this study it was verified the opportunity of implementations a vinasse concentration system as a way of reducing the water abstraction by the plants. This is due to the fact that much of the water leaving the production process comes in the form of vinasse and, therefore, it is possible to recover this water by means of a concentration system, so that after treatment it returns to the process.

The vinasse is generated at a rate of $13 \mathrm{~L}$ on average for each liter of ethanol produced. Therefore, the concentration system can result in the sale of a new product, which is the biofertilizer composed of residues such as filter cake, boiler ash and concentrated vinasse, sources of nitrogen, phosphorus and potassium. This is a practice that helps to reduce the use of chemical fertilizers in crops and is well regarded from the point of view of social responsibility (Neamhom et al., 2016; Silalertruksa et al., 2017). The recycling of nutrients through the use of vinasse and its biofertilizers represents

Table 7

Possibilities of interventions for the disposal of waste and effluents and its classification, according to the $\mathrm{CP}$ intervention levels

\begin{tabular}{|c|c|c|}
\hline $\begin{array}{l}\text { Level 1: Technological change } \\
\text { alternatives }\end{array}$ & Level 2: Internal recycling of waste/water-based effluents & Level 3: External recycling of waste/water-based effluents \\
\hline $\begin{array}{l}\text { - Replacement of the spray cooling } \\
\text { system with the cooling tower water } \\
\text { for reuse }\end{array}$ & $\begin{array}{l}\text { - Reuse of sugarcane cleaning water by destinating it to the } \\
\text { tillage (vertical integration) }\end{array}$ & $\begin{array}{l}\text { - Reuse of sugarcane cleaning water destinated to the } \\
\text { outsourced tillage (horizontal integration) }\end{array}$ \\
\hline $\begin{array}{l}\text { - Treatment of the water contained in } \\
\text { the effluent }\end{array}$ & $\begin{array}{l}\text { - Effluent treatment from the boiler gases used in the } \\
\text { cleaning of sugarcane in receiving and in the crop } \\
\text { (vertical integration) }\end{array}$ & $\begin{array}{l}\text { - Effluent treatment of the boiler gases incorporated into } \\
\text { the vinasse and discarded in the crop (horizontal } \\
\text { integration) }\end{array}$ \\
\hline $\begin{array}{l}\text { - Installation of the aerator to increase } \\
\text { the thermal efficiency of the boiler } \\
\text { - Replacement of the heat exchangers } \\
\text { plates for temperature reduction } \\
\text { chillers in wine fermentation }\end{array}$ & $\begin{array}{l}\text { - Effluent from the boilers incorporated into the vinasse } \\
\text { and destined to the crop (vertical integration) } \\
\text { - Sludge incorporated into the pie and into the crop } \\
\text { (vertical integration) }\end{array}$ & $\begin{array}{l}\text { - Boiler discharge effluent incorporated into the vinasse } \\
\text { and for the crop (horizontal integration) } \\
\text { - Sludge incorporated into the pie and the crop (horizontal } \\
\text { integration) }\end{array}$ \\
\hline $\begin{array}{l}\text { - Use of closed systems in the } \\
\text { production process only making the } \\
\text { replacement of losses }\end{array}$ & $\begin{array}{l}\text { - Condensed evaporators effluent destined to the boilers } \\
\text { and tillage (vertical integration) }\end{array}$ & $\begin{array}{l}\text { - Condensed effluent evaporators incorporated into the } \\
\text { vinasse and the crop (horizontal integration) }\end{array}$ \\
\hline \multirow[t]{6}{*}{$\begin{array}{l}\text { - Replacement of the traditional } \\
\text { system of cleaning sugarcane (with } \\
\text { water) with the dry-cleaning system }\end{array}$} & $\begin{array}{l}\text { - Barometric effluents from the condensers intended for } \\
\text { distillation of ethanol and agriculture (vertical } \\
\text { integration) }\end{array}$ & $\begin{array}{l}\text { - Barometric effluents from condensers destinated to fields } \\
\text { (horizontal integration) }\end{array}$ \\
\hline & $\begin{array}{l}\text { - Rectified solution of phlegma destined to the production } \\
\text { process (vertical vertical) }\end{array}$ & $\begin{array}{l}\text { - Rectified solution of phlegma destinated for marketing } \\
\text { and tillage (since there is decantation of fuel oil) } \\
\text { (horizontal vertical) }\end{array}$ \\
\hline & $\begin{array}{l}\text { - Ethanol returned to the steering wheel (production } \\
\text { process) }\end{array}$ & $\begin{array}{l}\text { - Effluent from the washing of the vats incorporated into } \\
\text { the vinasse and tillage (horizontal integrational) }\end{array}$ \\
\hline & $\begin{array}{l}\text { - Effluent from the washing of floors and equipment } \\
\text { incorporated into the vinasse and tillage (vertical } \\
\text { integration) }\end{array}$ & $\begin{array}{l}\text { - Effluent wash the floors and equipment incorporated into } \\
\text { the vinasse and tillage (horizontal integration) }\end{array}$ \\
\hline & $\begin{array}{l}\text { - Effluent from the washing of the vats incorporated into } \\
\text { vinasse and intended for farming }\end{array}$ & - Gross ethanol for marketing (second ethanol) \\
\hline & $\begin{array}{l}\text { - Settled solids destinated to the tillage (vertical } \\
\text { integration) }\end{array}$ & $\begin{array}{l}\text { - Waste from ethanol dehydration destined for landfills } \\
\text { - Decanted solids destinated for agriculture (horizontal } \\
\text { integration). }\end{array}$ \\
\hline
\end{tabular}


a substantial saving for sugarcane industries in Brazil, where practically all Potassium fertilizers are imported (Scarpare et al., 2016).

However, it is worth noting that this is a decision for cases where water restrictions are very critical, since this concentration system requires energy integration with the plant and has high costs of implementation.

\subsection{Analyze water consumption in processes and identify improvement opportunities}

In sugar-energy plants it is important to analyze the water consumption in the processes of vats, must, broth and vapor condensers coolings, since these processes generally consume large volumes of water. Thus, with regard to the reduction of water consumption in the aforementioned processes, the conduction of the present study allowed to identify the following opportunities of improvements:

- Use condensed water and, if necessary, cooling it before use; Use fluids, such as the rectified solution of phlegma to clean tanks and equipment; - Work with larger wine concentrations to reduce the volume of vinasse; and

- Measure the wastewater indicators to monitor how much of the water abstracted is being lost.

The opportunity to take advantage of condensed water is due to the fact that in the industrial process an important part of the water used comes from the cane itself, in the form of condensed vegetables. Considering that cooling systems consume much water, it should be sought to cooling using other fluids that need to be heated (water/energy integration). As such refrigeration systems are in closed circuits, in this case, the required water would need to be replaced only in cases of drag losses and evaporation.

In addition, in order to identify improvements, it is necessary the plant technicians to have a systemic view of the whole industrial production process and to verify the economic gains resulting from the interventions. In this sense, it was also verified the need to provide sources of financing and incentive so that the plants can carry out the necessary interventions to rationalize the use of water.

The implementation of these $\mathrm{CP}$ opportunities contribute to the rationalization of water abstraction and consumption and its continuous improvement must be done through regular reviews on the entire process. In this way, once the plant has implemented any measure, it is necessary to continue monitoring the water consumption in the process, in order to identify the possibility of implementing new improvements on the minimization of wastewater and environmental protection.

\section{Conclusion}

The sugar-energy plants use a high volume of water in their production process. Therefore, this study identified, through a literature review on CP and the conduction of four case studies, opportunities to reduce the use of water in the productive processes of sugar-energy plants, making them more efficient and sustainable. Among the opportunities for improvement identified, it should be highlighted: the use of dry-cleaning system for sugarcane cleaning, classification and analysis of effluents, analysis of the water consumption in the processes, the use of the system of concentration of vinasse, and other changes in the production process with implementation of new technologies (equipment) that reduce water use and promote power generation.

It is concluded that a practical approach, based on the foundations of Cleaner Production, can contribute to the solution of environmental problems in sugar-energy plants. The proposed interventions concern changes in the production process and/or the implementation of new technologies to prevent the generation of waste and effluents, reduce costs and incorporate environmental and economic gains through the efficient use of raw materials, water and energy.

In addition, it is worth noting that despite the benefits that Cleaner Production can bring to the companies that use it, not all of them can implement this tool with success (Moors et al., 2005; Bonilla et al., 2010). According to Shi et al. (2008), the successful implementation of $\mathrm{CP}$ depends on internal cooperation and involvement of the top management and technical and operational teams, besides incentives for funding, regulatory and market policies. In this sense, the proposed recommendations may have greater or lesser applicability depending on the organizational, economic and geographical context in question.

With regard to sector-specific regulations, it is important to highlight that they are an important means to promote water management, since they establish limits for the use of water in the production process of sugarcane plants and provide goals to be achieved in order to recognize and reward companies engaged with water management. The Brazilian environmental protocol in force in the State of São Paulo is an example of a regulation whose actions and goals have helped the plants to improve their water management. Through regulations such as this one, it is possible to establish best practices to avoid the open-air burning of bagasse and by-products of sugarcane, to protect the riparian areas of sugarcane properties, to reduce water consumption per ton of sugarcane processed, etc.

The main scientific contribution of this study is the systematization of $\mathrm{CP}$ interventions in sugar-energy plants, based on findings from literature review and empirical studies, in order to create an expansion of the existing theory. It is also worth noting it is an unpublished work, since no CP interventions have been proposed in the context studied (sugar-energy plants) and in the form presented in this article (focusing on the proposal of improvement opportunities and identification of challenges to reduce water consumption). As applied contribution, it should be highlighted the high degree of feasibility of the interventions proposed.

This research has geographic limitations related to the location of the companies studied, which did not allow the generalization of the results. Therefore, it is suggested for future research to carry out a survey with a larger sample and, if possible, involving different countries, so that the findings of this work can be verified from a broader point of view. It is also suggested that the improvement opportunities proposed in this work be applied and a comparative study be conducted to evaluate the results obtained with their use. 
Appendix A. Data collection protocol

\begin{tabular}{|c|c|c|c|}
\hline \multirow[t]{3}{*}{ Interview script } & \multicolumn{3}{|c|}{ Data collection instruments } \\
\hline & \multicolumn{2}{|l|}{ Interview } & \multirow{2}{*}{$\begin{array}{l}\text { On-site Document } \\
\text { visitation Analysis }\end{array}$} \\
\hline & $\begin{array}{l}\text { Production } \\
\text { manager }\end{array}$ & $\begin{array}{l}\text { Process } \\
\text { manager }\end{array}$ & \\
\hline \multicolumn{4}{|c|}{$\begin{array}{l}1 \text { - Has the spray cooling system been replaced by the cooling tower for recycled water? If so, what were the } \\
\text { results? }\end{array}$} \\
\hline \multicolumn{4}{|c|}{2 - What treatments are used to reuse effluent water? } \\
\hline \multicolumn{4}{|c|}{3 - Is there any deaerator to increase the thermal efficiency of the boiler? } \\
\hline \multicolumn{4}{|c|}{$\begin{array}{l}4 \text { - Were the heat exchangers to plates replaced by chillers of reduction of temperature in the fermentation of } \\
\text { the wort? If so, what were the results? }\end{array}$} \\
\hline \multicolumn{4}{|c|}{5 - Does the plant employ closed systems in the production? How do it work? } \\
\hline \multicolumn{4}{|c|}{6 - Does the plant have a closed circuit for the cleaning of sugarcane and treatment of reuse water? } \\
\hline \multicolumn{4}{|c|}{7 - Is the water circuit in the cane cleaning closed? How do it work? } \\
\hline \multicolumn{4}{|l|}{8 - Water consumption is: } \\
\hline \multicolumn{4}{|l|}{ Less than $0.7 \mathrm{~m}^{3} /$ ton sugarcane } \\
\hline \multicolumn{4}{|l|}{ Between 0.7 and $1 \mathrm{~m}^{3} /$ ton of sugarcane } \\
\hline \multicolumn{4}{|l|}{ Between 1 and $2 \mathrm{~m}^{3} /$ ton of sugarcane } \\
\hline \multicolumn{4}{|c|}{ Above $2 \mathrm{~m}^{3} /$ ton of sugarcane } \\
\hline \multicolumn{4}{|c|}{$\begin{array}{l}9 \text { - Does the water need to be pumped for cleaning the cane at the reception? Is there electricity consumption in } \\
\text { this process? }\end{array}$} \\
\hline \multicolumn{4}{|c|}{10 - What is the final destination of the water used at the reception to clean the cane? } \\
\hline \multicolumn{4}{|l|}{11 - Is there water consumption at the reception? How does this mechanism work? } \\
\hline \multicolumn{4}{|l|}{12 - Does the plant have the dry-cleaning system? How does this mechanism work? } \\
\hline 13. Is the sugarcane separated from the sugarcane being burned in the boiler? & & & \\
\hline
\end{tabular}

\section{References}

Birru, E., Erlich, C., Beyebe, G.B., Martin, A., 2016. Upgrading of a traditional sugar cane mill to a modern mill and assessing the potential of energy saving during steady state and transient conditions-part II: models for a modified cogeneration unit. Biomass Convers. Biorefiner 6, 233-245.

Bonilla, S.H., Almeida, C.M.V.B., Giannetti, B.F., Huisingh, D., 2010. The roles of cleaner production in the sustainable development of modern societies: an introduction to this special issue. J. Clean. Prod. 18, 1-5.

Bueno, M.P., Salvador, N.N.B., 2012. Sustainability of the Business Management Practices of Two Sugar Cane Plants in the State of São Paulo (Sustentabilidade das Práticas de Gestão Empresarial de Duas Usinas de Açúcar e Álcool de CanaDe-Açúcar no Estado de São Paulo). In: Proceedings of the 7th Congress on the Environment. UFSCar - Federal University of São Carlos.

Elia Neto, A., Shintaku, A., Donzelli, J.L., Conde, A.J., Pio, A.A.B., Giannetti, F.H., 2009. Manual de Conservação e reuso de água na Agroindústria Sucroenergética. In: Handbook on Water Conservation and Reuse in Agroindustry. Cane Technology Center, Brasília, pp. 69-176. Chap. 5.

EMBRAPA, 2017. Who We Are. https://www.embrapa.br/quem-somos/ (Accessed 03 July 2017).

Figueiredo, P.N., 2017. Micro-level technological capability accumulation in developing economies: insights from the Brazilian sugarcane ethanol industry. J. Clean. Prod. 167, 416-431.

Getzner, M., 2002. The quantitative and qualitative impacts of clean technologies on employment. J. Clean. Prod. 10, 305-319.

Hoof, B.V., Thiell, M., 2015. Anchor company contribution to cleaner production dissemination: experience from a Mexican sustainable supply programme. J. Clean. Prod. 86, 245-255.

Jupp, V., 2006. The Sage Dictionary of Social Research Methods. Sage Publications Ltd., New York, pp. 79-249.

Kent, G.A., Scott, S.J., 2009. Design, manufacturing and maintenance of sugar milling equipment: observations from the 2008 International Society of Sugar Cane Technologists engineering workshop. Sugar Cane Technol. 31, 481-488.

Kheerthipala, A.P., 2016. Development of sugar industry in Sri Lanka. Sugar Tech. 18 (6), 612-626.

Klemes, J.J., Varbanov, P.S., Huisingh, D., 2012. Recent cleaner production advances in process monitoring and optimization. J. Clean. Prod. 34, 1-8.

Laforest, V., Raymond, G., Piatyszek, E., 2012. Choosing cleaner and safer production practices through a multi-criteria approach. J. Clean. Prod. 1-14.

Liu, Y., 2014. Barriers to the adoption of low carbon production: a multiple-case study of chinese industrial firms. Energy Policy 67, 412-421.

Martins, R.A., 2010. Abordagens quantitativa e qualitativa: metodologia de pesquisa em engenharia de produção e gestão de operações - (Quantitative and qualitative approaches: research methodology in production engineering and operations management. In: Miguel, P.A.C. (Ed.), Metodologia De Pesquisa Em Engenharia De Produção, Research Methodology in Production Engineering, vol. 3. Elsevier, Rio de Janeiro, pp. 45-46.

Medeiros, D.D., Calábria, F.A., Silva, G.C.S., Filho, G.C.C.S., 2007. Implementation of Cleaner Production as a tool of continuous improvement. Production 17 (1), 109-128.
Molinaria, M.A., Quelhasb, O.L.G., Nascimento filho, A.P., 2013. Evaluation of cleaner production opportunities for the reduction of solid waste in the manufacture of paints (Avaliação de oportunidades de produção mais limpa para a redução de resíduos sólidos na fabricação de tintas). Production 23 (2), 364-374.

Moors, E.H.M., Mulder, K.F., Vergragt, P.J., 2005. Towards cleaner production: barriers and strategies in the base metals producing industry. J. Clean. Prod. 13, 657-668.

Neamhom, T., Polprasert, C., Englande Jr., A.J., 2016. Ways that sugarcane industry can help reduce carbon emissions in Thailand. J. Clean. Prod. 131, 561-571.

Novacana, 2015. The performance of the brazilian mills in the 2014/15 and 2015/16 harvests. http://www.novacana.com. (Accessed 4 July 2015).

Omena, S.P.F., Callado, N.H., Pedrosa, V.A., Pimentel, I.M.C., Menezes, A.C., Torquato, J.R.H., Lopes, J.C., Silva, J.B., 2004. Melhoria da qualidade ambiental, por meio da recirculação de água de limpeza da cana na indústria sucroalcooleira (Improvement of the environmental quality, through the recirculation of sugar cane cleaning water in the sugar-alcohol industry.). In: VII Symposium on Water Resources of the Northeast 30 November to 3 December 2004.

Payne, J.H., 1990. Operations in the production of sugar from sugar cane) (Operações unitárias na produção de açúcar de cana-de-açúcar). Honolulu, Havaí. Nobel/ STAB.

Rodrigues, A.M., Rebelato, M.G., Paixão, R.B.S., Zeviani, C.H., 2014. Gestão ambiental no setor sucroenergético: uma análise comparativa (Environmental management in the sugarcane industry: a comparative analysis). Online Prod. Mag. 14 (4), 1481-1510.

Rodrigues, J.A.R., 2011. Do engenho à biorrefinaria. A usina de açúcar como empreendimento industrial para a geração de produtos bioquímicos e biocombustíveis (From sugar mill to biorefinery. The sugar mill as an industrial enterprise for the generation of biochemicals and biofuels). Quim. Nova 34 (7), 1242-1254. Instituto de Química, Universidade de Campinas.

Sampieri, R.H., Collado, C.F., Lucio, P.B., 2006. Research Methodology. McGraw-Hill, São Paulo.

Santos, J.G., Carneiro, V.C.V., Ramalho, A.M.C., 2015. Sustainability and cleaner production: a study on the implications of enterprise competitive advantage. Rev. Metrop. Sustentabilidade 5, 34-48.

Scarpare, et al., 2016. Sugarcane water footprint under different management practices in Brazil: tiete/Jacaré watershed assessment. J. Clean. Prod. 112, 4576-4584.

Scheiterle, L., Ulmer, A., Birner, R., Pyka, A., 2018. From commodity-based value chains to biomass-based value webs: the case of sugarcane in Brazil's bioeconomy. J. Clean. Prod. 172, 3851-3863.

Shi, H., Peng, S.Z., Liu, Y., Zhong, P., 2008. Barriers to the implementation of cleaner production in Chinese SMEs: government, industry and expert stakeholders perspectives. J. Clean. Prod. 16, 842-852.

Silalertruksa, T., Pongpat, P., Gheewala, S.H., 2017. Life cycle assessment for enhancing environmental sustainability of sugarcane biorefinery in Thailand. J. Clean. Prod. 140, 906-913.

Silva, D.A.L., Delai, I., Castro, M.A.S., Ometto, A.R., 2013. Quality tools applied to Cleaner Production programs: a first approach toward a new methodoloy. J. Clean. Prod. 47, 174-187. 
Silva, A.S., Medeiros, C.F., Vieira, R.K., 2017. Cleaner production and PDCA cycle: practical application for reducing the cans loss index in a beverage company. J. Clean. Prod. 150, 324-338.

Solomon, S., 2016. Sugarcane production and development of sugar industry in India. Sugar Tech. 18 (6), 588-602.

Stupiello, J.P., 2014. Conversando com a cana: cinzas no açúcar: participação do ácido aconítico (Talking with sugarcane: ashes in sugar: participation of aconitic acid). Stab açúcar, álcool subprodutos 32, 10.

Van Hoof, B., Lyon, T.P., 2013. Cleaner production in small firms taking part in Mexico's sustainable supplier program. J. Clean. Prod. 41, 270-282.

Werner, E.M., Bacarji, A.G., Hall, R.J., 2009. Produção mais limpa: conceitos e definições metodológicas (Cleaner production: concepts and methodological definitions). In: SEGeT - Simpósio de Excelência em Gestão e Tecnologia, Rio de
Janeiro, Brazil, vol. 1, pp. 1-15.

Yin, R.K., 2014. Case Study Research: Design and Methods, 5 Ed. SAGE Publications, New York.

Zeng, S.X., Meng, X.H., Yin, H.T., Tam, C.M., Sun, L., 2010. Impact of cleaner production on business performance. J. Clean. Prod. 18, 975-983.

Zeviani, C.H., Rodrigues, A.M., Rebelato, M.G., 2013. Elaboração de um roteiro de pesquisa para avaliação do desempenho ambiental em empresas industriais (Elaboration of a research guide to evaluate environmental performance in industrial companies). In: 1510 Anais do XXXIII Encontro Nacional de Engenharia de Producão (ENEGEP). ABEPRO, Salvador, Brazil.

Zhou, M., Pan, Y., Chen, Z., Yang, W., Li, B., 2012. Selection and evaluation of green production strategies: analytic and simulation models. J. Clean. Prod. 26, 9-17. 